\title{
AUTOMATIC DETECTION OF SIGNIFICANT VARIATION FROM DESIGNED INTENT UTILIZING SURVEY DATA CIAMS: CONSTRUCTION INFORMATION AND MANAGEMENT SYSTEM
}

\author{
DeWitt T. Latimer IV ${ }^{1}$, Ogbemi Hammond ${ }^{2}$, Richard Hallon', \\ Christian T Stidsen ${ }^{2}$, Sze-Lok Lam ${ }^{2}$ \\ ${ }^{1}$ Robotics Institute, School of Computer Science \\ Carnegie Mellon University \\ dlatimer@cs.cmu.edu \\ ${ }^{2}$ Civil and Environmental Engineering Department \\ Carnegie Mellon University \\ Pittsburgh, PA 15213 \\ okh@andrew.cmu.edu,rhallon@andrew.cmu.edu,stidsen@andrew.cmu.edu, \\ slam@andrew.cmu.edu
}

\begin{abstract}
Current practice of providing an "As-built" survey as the completion of work should not be the only mechanism for observation of problems in the construction process. In many cases, survey data is available early in a project, but may not yet have been reconciled against the engineering intent. CIAMS (Construction Information And Management System) is proposed to drive the rapid reconciliation of survey data against engineering design intents through information automation. We will also describe other applications that could benefit from such rapid automated metrology techniques.
\end{abstract}

Keywords: Construction Automation, Construction Metrology, Information Management System, Construction Assessment, Decision Support System.

\section{INTRODUCTION}

Lack of information about the timely "as-is" status of the project site can lead to unforeseen problems, delays and waste for construction companies and their clients. More timely availability of survey data can realize more efficient management and an ability to catch and solve problems earlier in an integrated construction process. Any attempt to automate such a large system needs to be focused not only on the theoretical notions of construction project management, but must be based on actual projects in the field.

\subsection{Construction Models}

There are three types of construction models we will consider: construction models, "as-is" models, and "as-built" models. We will consider these models separately, although they are normally represented as one evolving document.
Construction models, which we consider to be the construction design drawings and documents, are the technical solution that conforms to the functional requirements of the system being designed [10]. This is the model that is communicated from the designers (be they architects, civil engineers, mechanical engineers, or others) to the construction management company.

"As-is" models depict the state of the construction project site at a given time, before completion of the project. These types of models are not often generated due to the large amount of effort and money necessary for a complete model.

"As-built" models depict the final state of the construction project at the time when the facility is delivered from the construction management company to the client. These models typically only commence on final completion of work on the site.

\subsection{Reconciliation of Actual to Design}


As progress is made to the construction site, it is necessary to assess how well the results of construction activities match the design. Differences between the design and the actual project are noted.

\subsection{Client and Sponsor}

Adtranz NA (Daimler-Chrysler Rail Systems of North America) provides mass transit systems, such as the INNOVIA [1], to a global market of clients. These clients have installations in diverse construction settings.

\subsection{The INNOVIA System}

Adtranz has developed the INNOVIA people mover system. The goal of INNOVIA is to transport people in rubber tire, automatically guided vehicles on a dedicated track. Crucial in the construction of these tracks (called guide ways) is the placement of the guide rail. Perpendicular to the guide rail, specific distances are set as a safety envelope (see Figure 1), inside which there may be no obstructions.

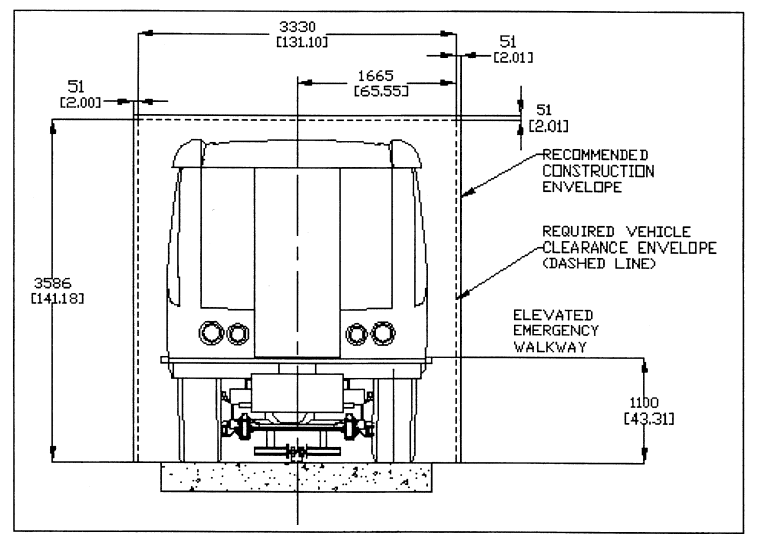

Figure 2 - Safety envelope for the INNOVIA[2]

\section{PROBLEM DESCRIPTION}

In automatic problem detection, we look to detect early where design constraints are being violated. In our demonstration system, we are examining one specific design constraint, the examination for where incursions have occurred in a safety envelope around where an autonomous mass transit vehicle will operate [2].

This information on violations of constraints during the construction process must be relayed to many parties, such as project management, designers and engineers providing new solutions, and the construction contractors.
The current practice to detect incursions is to measure from the installed guide beam at potential problem locations. Adtranz acquires survey data in the form of survey reports. These reports can sometimes be available (as in the case of the "Asbuilt" survey) in a typed form. Another current main source for data is in the form of CAD drawings. These design drawings contain detailed initial design considerations of the structure being built.

Adtranz does not maintain a computerized "as-is" model of the construction site. A retained civil engineering design firm is contracted to maintain information about the model in the form of plans and progress reports.

Currently, formal reports are generated and given to Adtranz at the end of construction, when the final survey is completed. These are standard survey reports, which include drawings of sections and the location of survey points. The final survey report format varies depending on the needs of the client. Reports of incursions on the safety envelope are compiled from data obtained by a Styrofoam bumper test. As regards to user interface, communication is in the form of verbal and written.

\section{PROPOSED SYSTEM}

CIAMS is a user-centric system design, from which the system architecture was developed. CIAMS will receive input about the design models and survey points, automatically reconcile the design with the survey, determine if the safety envelope design constraint may be violated, and generate reports as needed.

According to Adtranz, for the improvement to be feasible, the data quality and its volume should be at least equal to the current practice right now, and the construction process should not be significantly altered.

\subsection{User Population}

Since the primary function of the CIAMS system is to collect and use initial design and survey information for later updates, and provide resulting reports of incursions on the safety envelope, its primary users fall within the key groups that manage the construction process. Figure 2 indicates the nature of relationships between CIAMS and the various user populations, and the general flow of information and activity as it relates to the CIAMS system.

\subsection{Current Practice}




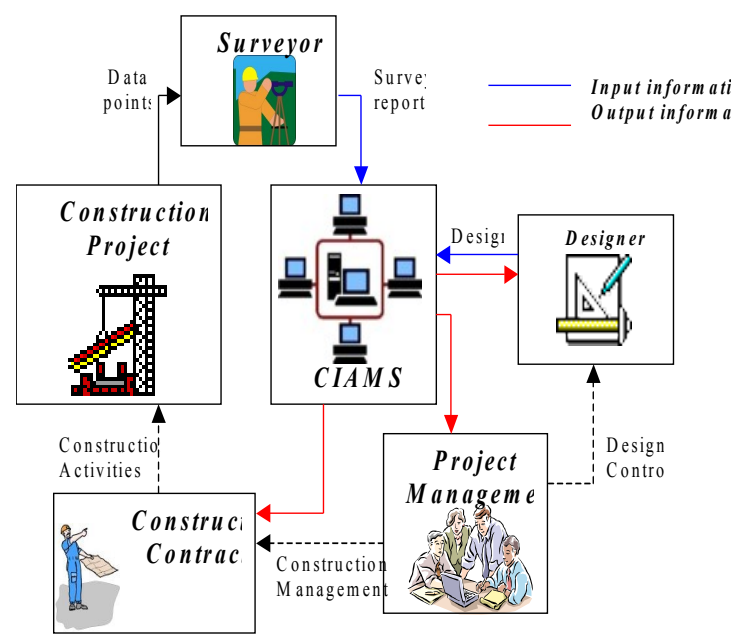

Figure 2 - Depicting the interaction of the various entities with the proposed CIAMS system

On the highest level of management, there is a matrix of five key people that oversee a project: the program manager, program administrator, lead engineer, operations program controller, and the field site manager.

The program manager is the leader of the team, assigned with general coordination of projects in general, and interaction with clients. The program administrator is responsible for financial and schedule control and reporting. The lead engineer coordinates technical/engineering elements of the project; normally there are lead engineers assigned for mechanical, civil, and electrical subsystems under this primary lead engineer. The operations program controller coordinates purchasing and manufacturing. The field site manager is responsible for the general management and control of interfaces within the geographical site of the construction project; this individual is the central coordinator of all on-site activities.

At a lower level of management, there will be other users, which most likely will produce the information that the CIAMS system will need for proper functioning. A complete list of personnel with clearance is dependent on the contract that is binding the construction process. Some of these people are companies contracted by Adtranz, companies contracted by non-Adtranz entities (such as the client of Adtranz), field engineers, inspectors, field site management assistants, designers, and surveyors.

\subsection{System Architecture}

An initial system design approach has been taken to divide this project into manageable subsystems. These subsystems include survey data acquisition, CAD interface, database, "as-is" modeling, automated analysis, report generation, and user interface.
CIAMS highest-level architecture is essentially a feed-forward system. The architectural intent of the system is depicted in Figure 3. Information begins at the top of the figure, with the CAD and survey data acquisition subsystems. Then information flows into the information management modules, to be stored by the database, utilized by the "as-is" modeling subsystem, and flowed back to the users through the report generation and user interface subsystems. Another level, automated analysis, attaches to the data stored in the system to provide useful derivative information, such as the potential of an incursion on the safety envelope.

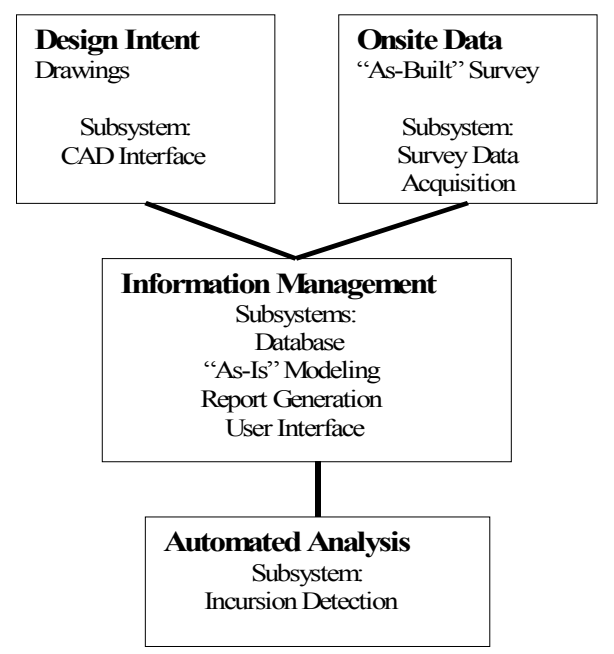

Figure 3 - System Design Schematic

The survey data acquisition defines methods for inserting survey data [3] into the CIAMS system while the CAD Interface defines methods for exchanging design information with CAD systems [5] [6]. The means by which this information is acquired vary, while traditionally these are deliverable reports specified in contracts. In an automated site, a system to transfer data in a standard format [8] is necessary.

The database is responsible to safeguard all nonvolatile data in the system and to provide security of said data against piracy. The design of the structures within the database is crucial, yet much attention has been given to standardizing representations of construction designs [4] and database designs [9].

The "as-is" modeling subsystem generates a world model that is usable to other subsystems within CIAMS from the CAD models and the survey data [10]. Improving the design and "As is" reconciliation means applying automated techniques to relate survey data to design models, typically in CAD. In this we explore the automated markup of design also known as "intent drawings of the site with survey data. While this is what happens to some extent as 
surveyors markup a plan on the site, our main contribution will be to provide a "fresh" plan that shows the structures at the points they actually occupy.

The automated analysis subsystem evaluates the world model for incursions on the safety envelope.

The report generation subsystem watchdogs the database and other subsystems for data that must be reported to one or more users. It then is responsible to generate the report for those users. This system is essential for construction process integration. Although highly detailed reports can be generated, different users have different needs. The program manager's report should only indicate that there might be a problem in a given area. However, the Lead Engineer should receive a detailed report, not only about the existence of the problem, but also about the scale and other details necessary to begin resolving the engineering problem.

The user interface subsystem interfaces between all the subsystems within CIAMS and the user. As such, the user interface is responsible to manage all the interactions with the user and appropriately integrate the CIAMS system into the construction management model being used by Adtranz. Also, since the human is being taken "out of the loop" some attention has been paid for cases when CIAMS does not have sufficient information to determine the location of features. Again, this subsystem is highly important for good construction process integration. The choice of user interface methods (for example a proprietary system, such as Lotus Notes ${ }^{\mathrm{TM}}$, or through simple clear-text emails) indicates not only how closely the system can be integrated with the current process, but also how much training may be required for users as the system is introduced. The users may be isolated from each other geographically, and thus attention is paid to distributing the interaction [11].

\subsection{Implementation}

The CIAMS system as described has not yet been implemented. However, due to the large number of COTS and research packages that make up the subsystems of the project, the extensions necessary appear to be feasible.

Use cases have been developed that provide a general road map of the types of interactions between the user population and CIAMS. Developed scenarios addressed issues of initialization, survey-reconcileanalyze-report cycle, re-design, and system security.

While initialization may seem trivial, there are many aspects to starting an information system in a project. Tools must not break, and indeed have reasonable performance if some information has not yet been added to the system.

The survey-reconcile-analyze-report cycle is the mode in which a project will spend most of its time. Survey crews will indicate new survey points to the CIAMS system. CIAMS then performs its functions as described in the architecture section above, with project management receiving reports on the status of the construction site.

The redesign use case is of particular importance to a successful system. When problems are discovered, new designs are sometimes necessary to correct the problem. Thus CIAMS addresses situations in which these new designs are being developed and changes are reported as necessary.

Security in any system where the integrity of the data is critical is of paramount importance and should not be an afterthought [7]. Security in CIAMS was addressed early in the requirements phase, and those requirements were constantly carried forward. In CIAMS, the risks associated with a compromised system are tremendous - from the potential loss of proprietary designs to the malicious injection of faulty designs to sabotage the project.

\section{OTHER APPLICATIONS}

During the analysis phase, several additional extensions and applications realms showed promise for future exploration but were not modeled in CIAMS.

System integration of schedule, cost and resource management within CIAMS might be the basis through which Adtranz improves on the knowledge management within the company. Information will be readily available to anyone concerned with the project on and off the site, thereby improving the rates on decision-making and information retrieval.

Local site information like price indices, lists of reliable contractors, and other relevant information should be included in CIAMS to aid Adtranz in their future bidding process.

In addition to civil construction, CIAMS could be expanded for use with other types of construction and installation. The precision and progress of Electrical or Mechanical system installations could be monitored through CIAMS by submitting design drawings, along with the corresponding survey data. For INNOVIA, these installations could include the power rail, deicing system, or switches, among others. It is also important to note that CIAMS has a 
wide scope of construction applications that is not limited solely to people mover projects.

In addition to detecting incursions on the safety envelope, it is possible to analyze the incoming data for other spatial concerns. These additional concerns include such issues as station docking compliance and door alignment.

\section{SUMMARY}

Lack of information about the current "as-is" status of the project site can lead to unforeseen problems, delays and waste for construction companies and their clients. More timely availability of survey data can realize more efficient management and an ability to catch and solve problems earlier in the construction process.

Integration with the current survey and construction process is essential due to the fact that the construction industry, as a whole, is very risk-adverse in changing processes. Thus they will more easily adopt tools that more efficiently accomplish tasks in their current process, as opposed to adopting or replacing processes and tasks.

CIAMS is extensible to allow input of survey data from multiple types of "surveyors". In addition to the traditional survey company, sensors and robots could deliver survey data directly to CIAMS. Future work is currently being planned to examine the feasibility and prototype a deployable automated assessment sensory system to collect survey points as needed.

Since CIAMS is aware of the design and "As-is" status of the construction site, it can generate reports to keep project management aware of the status of the construction site. Furthermore, since the designer had access to current drawings of the actual state of the site through CIAMS to aid with redesign, the designer and project management are able to test potential solutions for incursion before implementation.

\section{Acknowledgments}

Thanks to Adtranz North America for opening their doors and providing funding for this research. The Pennsylvania Infrastructure Technology Alliance for providing funding. Thanks to James Garrett and Mark Patton, faculty members of the Carnegie Mellon Civil and Environmental Engineering Department who gave guidance to this project. Additional thanks for support from the National Institute for Standards and Technology.

\section{REFERENCES}

[1] Adtranz ABB Daimler-Benz Transportation (North America) Inc., "Automated Guideway Transit Systems", Adtranz publication number USTRA9602

[2] Adtranz ABB Daimler-Benz Transportation (North America) Inc., "INNOVIA Automated Guideway Transit System Planning Guide", November 1999

[3] Brinker, Minnick, "The Surveying Handbook", Harper \& Row Publishers Inc., 1987

[4]Eastman, Tay Sheng Jeng, “A Database Supporting Evolutionary Product Model Development for Design", Construction Automation, Page 305-323, Volume 8, Number 3.

[5] Fenves, et al, "Concurrent Computer-Integrated Building Design”, Prentice-Hall Inc., 1994

[6] Kim, et al, "Managing Design Data in an Integrated CAAD Environment: A Product Model Approach", Automation in Construction, Volume 7, Number 1, Page 35-54, December 1997.

[7] McGraw, "Software Assurance for Security", Computer, Page 103-105, Volume 32, Number 4, April 1999

[8] Pfeffer, Latimer, "Toward Open Network DataExchange Protocols For Construction Metrology and Automation: LiveView", $16^{\text {th }}$ IAARC/IFAC/IEEE International Symposium on Automation and Robotics in Construction (ISARC), Madrid, Spain, Sep. 22-24, 1999

[9] Rezgui, et al, "An Information Management Model for Concurrent Construction Engineering", Automation in Construction, Volume 5, Number 5, Page 343-355, October 1996.

[10] Wittenoom, "Automating Realization of Integrated Project Models", Construction Automation, Page 249-267, Volume 8, Number 3, February 1999.

[11] Zamanian, Pittman, "A Software Industry Perspective on AEC Information Distributed Collaboration", Construction Automation, Page 237248, Volume 8, Number 3, February 1999. 